Mazur Karol, Lewicki Marcin, Mazur Dominika, Tyniec Mateusz, Smoleń Agata. Effects of ashwagandha root extract on physical performance - a clinical review. Journal of Education, Health and Sport. 2021;11(12):337-343. eISSN 2391-8306. DOI http://dx.doi.org/10.12775/JEHS.2021.11.12.027

https://apcz.umk.pl/JEHS/article/view/JEHS.2021.11.12.027

https://zenodo.org/record/5807361

The journal has had 40 points in Ministry of Education and Science of Poland parametric evaluation. Annex to the announcement of the Minister of Education and Science of December 1, 2021. No. 32343. Has a Journal's Unique Identifier: 201159. Scientific disciplines assigned: Physical Culture Sciences (Field of Medical sciences and health sciences); Health Sciences (Field of Medical Sciences and Health Sciences).

Punkty Ministerialne z 2019 - aktualny rok 40 punktów. Zalącznik do komunikatu Ministra Edukacji i Nauki z dnia 1 grudnia 2021 r. Lp. 32343. Posiada Unikatowy Identyfikator Czasopisma: 201159. Przypisane dyscypliny naukowe:Nauki o kulturze fizycznej (Dziedzina nauk medycznych i nauk o zdrowiu); Nauki o zdrowiu (Dziedzina nauk medycznych i nauk o zdrowiu).

(1) The Authors 2021;

This article is published with open access at Licensee Open Journal Systems of Nicolaus Copernicus University in Torun, Polan

Open Access. This article is distributed under the terms of the Creative Commons Attribution Noncommercial License which permits any noncommercial use, distribution, and reproduction in any medium, provided the original author (s) and source are credited. This is an open access article licensed under the terms of the Creative Commons Attribution Non commercial license Share alike.

(http://creativecommons.org/licenses/by-nc-sa/4.0/) which permits unrestricted, non commercial use, distribution and reproduction in any medium, provided the work is properly cited. The authors declare that there is no conflict of interests regarding the publication of this paper.

Received: 05.12.2021. Revised: 23.12.2021. Accepted: 28.12.2021.

\title{
Effects of ashwagandha root extract on physical performance - a clinical review
}

\section{Karol Mazur ${ }^{1}$, Marcin Lewicki², Dominika Mazur ${ }^{3}$, Mateusz Tyniec ${ }^{4}$, Agata Smoleń ${ }^{5}$}

${ }^{1}$ Doctoral School, Medical University of Lublin, ul. Chodźki 7, 20-093 Lublin, Poland; mazurkarol79@gmail.com; https://orcid.org/0000-0003-3459-2588;

${ }^{2}$ Department of Epidemiology and Clinical Research Methodology of the Medical University of Lublin, ul. Radziwiłłowska 11, 20-080 Lublin, Poland; lewicki-marcin@wp.pl; https://orcid.org/0000-0003-1906-9326;

${ }^{3}$ Department of Obstetrics and Pathology of Pregnancy, Independent Public University Hospital No. 1 in Lublin, ul. Staszica 16, 20-081 Lublin, Poland; dominika.hul20@gmail.com; https://orcid.org/0000-0002-4689-0462;

${ }^{4}$ Clinical Department of Otolaryngology and Laryngological Oncology of Kazimierz Pułaski University of Technology and Humanities in Radom, Poland; ul. Aleksandrowicza 5, 26-617 Radom, mateusztyniec@yahoo.com; https://orcid.org/0000-0002-0191-319X;

${ }^{5}$ Department of Epidemiology and Clinical Research Methodology of the Medical University of Lublin, ul. Radziwiłłowska 11, 20-080 Lublin, Poland; agatasmolen@umlub.pl; https://orcid.org/0000-0003-0764-6667;

\section{Summary:}

Sport is an important aspect of human life, affecting mental and physical health. Physical activity is one of the most effective ways of preventing the diseases of civilisation, such as 
coronary heart disease, hypertension, obesity and diabetes. There are many substances and methods that are used by athletes to improve physical performance, increase muscle mass and strength, increase concentration or suppress excessive emotions or reduce body weight to improve sports results. However, there is a need for research to find natural substances of plant origin, the use of which will lead to an increase in physical performance and will be fully legal and without side effects. Some scientists are conducting research into the use of ashwagandha root extract to improve physical performance.

The aim of this study was to assess the efficacy and safety of ashwagandha root extract in the treatment of insomnia, anxiety and in reducing stress. Our study material consisted of publications, which were found in PubMed, ResearchGate and Google Scholar databases. In order to find the proper publications, the search has been conducted with the use of a combination of key words like: "ashawagandha", "physical performance", "physical endurance", "muscle strength". The first step was to find proper publications from the last 15 years. The second step was to carry out an overview of the found publications.

Key words: ashawagandha, physical performance, physical endurance, muscle strength

\section{INTRODUCTION AND PURPOSE}

Sport is an important aspect of human life, affecting mental and physical health. Physical activity is one of the most effective ways of preventing the diseases of civilization, such as coronary heart disease, hypertension, obesity and diabetes. It has been proven that physical activity, especially in middle-aged and elderly people, prolongs life and prevents premature death and serious diseases. Physical activity can lead to an increase in cardiac minute capacity, increase in cardiac blood flow and maximum oxygen saturation, decrease in resting heart rate and blood coagulation, improved gas transport, increase in lung ventilation, increased vital capacity of the lungs, decrease in respiratory resistance, decrease in respiratory rate, an increase in the speed of learning motor skills, increase in motor coordination and concentration, increase in bone mass, improving blood supply to bones and ligaments, increase in muscle mass, enzyme activity and efficiency of energy consumption and an 
increase in muscle power. Physical activity also has a beneficial effect on our psyche. Physical exertion is the best way to combat mental fatigue. In addition, physical activity plays an important integrating role if People are competing in one team. The idea of competition with others can have a mobilizing effect [1].

There are many substances and methods that are used by athletes to improve physical performance, increase muscle mass and strength, increase concentration or suppress excessive emotions or reduce body weight to improve sports results. Pharmacological doping is the use of performance-enhancing substances which are prohibited by the World Anti-Doping Agency (WADA). Some of these substances can induce disturbance of the body's homeostasis, in extreme cases leading to death. Therefore, there is a need for research to find natural substances of plant origin, the use of which will lead to an increase in physical performance and will be fully legal and without side effects. Some scientists are conducting research into the use of ashwagandha root extract to improve physical performance [2].

The aim of this study was to assess the effects of ashwagandha root extract on physical performance. Our study material consisted of publications, which were found in PubMed, ResearchGate and Google Scholar databases. In order to find the suitable publications, the search has been conducted with the use of a combination of key words like: "ashawagandha", "physical performance", "physical endurance", "muscle strength". The first step was to find suitable publications from the last 15 years. The second step was to carry out an overview of the found publications.

\section{LITERATURE REVIEW}

Wankhede et al. in their randomized, prospective, double-blind, placebo-controlled study assessed the effect of ashwagandha root extract supplementation on muscle strength and recovery. 57 young male subjects were randomized to receive two capsules a day $300 \mathrm{mg}$ ashwagandha root extract $(n=29)$ or placebo $(n=28)$ for 8 weeks. Participants were measured at the beginning and at the end of the study for: muscle strength (using the one-repetition maximum load for the bench press and leg extension exercises), muscle size, body composition (body fat percentage), serum testosterone levels and muscle recovery (using serum creatine kinase level). The results of this trail showed statistically significant increases in muscle strength on the bench-press exercise $(p=0.001)$ and the leg-extension exercise $(p=0.04)$, increase of testosterone level $(p=0.004)$ and decrease in body fat percentage $(p=0.03)$ and exercise-induced muscle damage as indicated by the stabilization of serum creatine kinase 
$(\mathrm{p}=0.03)$ in the ashwagandha $600 \mathrm{mg} /$ day group, in comparison with the placebo group. No serious adverse effects were reported by the participants. Consequently this trial proved the efficacy of ashwagandha root extract in increasing muscle strength and reducing recovery time [3].

Shenoy et al. in their randomized, prospective, double-blind, placebo-controlled trail investigated the effects of ashwagandha root extract on physical endurance in cyclists. 40 young male subjects were asked to take two capsules a day of $500 \mathrm{mg}$ ashwagandha root extract $(n=20)$ or placebo $(n=20)$ for 8 weeks. Participants were measured at the beginning and at the end of the study using FitNex 200 treadmill for: aerobic capacity in terms of maximal aerobic capacity $\left(\mathrm{VO}_{2}\right.$ max), metabolic equivalent (METs), respiratory exchange ratio (RER), and total time for the athlete to reach ones exhaustion stage. The results of this study revealed statistically significant improvement in $\mathrm{VO}_{2} \max (\mathrm{p}<0.001)$, METs $(\mathrm{p}<0.001)$, RER $(p<0.001)$, and time for exhaustion on treadmill $(p<0.001)$ in the ashwagandha 1000 $\mathrm{mg}$ /day group in comparison with the placebo group. No serious adverse effects were reported by the participants. So this study showed that ashwagandha root extract supplementation improved physical performance in cyclists [4].

Choudhary et al. in their randomized, prospective, double-blind, placebo-controlled study investigated the efficacy of ashwagandha root extract in enhancing cardio-respiratory endurance and improving the quality of life. 50 healthy males and females were randomized to receive two capsules a day of $300 \mathrm{mg}$ ashwagandha root extract $(n=25)$ or placebo $(n=25)$ for 12 weeks. Participants were measured at the beginning and at the end of the study for maximal aerobic capacity (VO2 max) using 20-m Shuttle Run Test. Their quality of life was assessed using World Health Organization- Quality of Life (WHO-QOL) questionnaire. The results of this trial showed statistically significant increase in the $\mathrm{VO}_{2} \max (\mathrm{p}<0.001)$ and WHO-QOL scores $(\mathrm{p}<0.05)$ in the ashwagandha $600 \mathrm{mg}$ /day group in comparison with the placebo group. No serious adverse effects were reported by the participants [5].

Sandhu et al. in their randomized, prospective, single-blind, placebo-controlled study checked the impact of ashwagandha root extract on physical performance and cardiorespiratory endurance. 40 young males and females were randomly assigned to one of four groups: group I receiving one capsule a day $500 \mathrm{mg}$ ashwagandha root extract $(\mathrm{n}=10)$, group II receiving one capsule a day $500 \mathrm{mg}$ Teminalia arjuna bark extract $(\mathrm{n}=10)$, group III receiving one capsule a day $500 \mathrm{mg}$ ashwagandha root extract and one capsule a day $500 \mathrm{mg}$ Teminalia arjuna bark extract $(n=10)$ or group IV receiving placebo $(n=10)$ for 8 weeks. Participants were measured at the beginning and at the end of the study for maximum velocity (using 
Kinematic Measurement System), average absolute and average relative power of the lower limbs (using Kinematic Measurement System), balance (using wobble board), maximum oxygen capacity $\left(\mathrm{VO}_{2} \max \right)$ and blood pressure. The results of this study showed statistically significant improvement in group $I$ in $\mathrm{VO}_{2} \max (p<0.001)$, maximum velocity $(p=0.005)$, average absolute power $(\mathrm{p}=0.002)$ and average relative power $(\mathrm{p}=0.007)$; in group II in VO2 $\max (p<0.001)$, average absolute power $(p=0.024)$ and systolic blood pressure $(p<0.001)$; in group III in VO2 max $(p<0.001)$, average absolute power from $(\mathrm{p}<0.001)$, average relative power $(\mathrm{p}<0.001)$, maximum velocity $(\mathrm{p}=0.004)$, systolic blood pressure $(\mathrm{p}<0.001)$ in comparison with the placebo group. No serious adverse effects were reported by the participants [6].

Malik et al. in their randomized, prospective, single-blind, placebo-controlled trail investigated the effects of ashwagandha root extract on physical endurance in hockey players. 32 males were asked to take two capsules a day $500 \mathrm{mg}$ ashwagandha root extract $(\mathrm{n}=16)$ or placebo $(n=16)$ for 8 weeks. Participants were measured at the beginning and at the end of the study for maximal aerobic capacity $\left(\mathrm{VO}_{2}\right.$ max) using Cooper 12 min. run test and for serum hemoglobin concentration $(\mathrm{Hb})$. The results of their study revealed statistically significant increase in the $\mathrm{VO}_{2} \max (\mathrm{p}<0.01)$ and $\mathrm{Hb}(\mathrm{p}<0.01)$ in the ashwagandha $1000 \mathrm{mg} /$ day group in comparison with the placebo group. No serious adverse effects were reported by the participants. So this study showed that ashwagandha root extract supplementation improved physical performance in hockey players [7].

Tripathi et al. in their prospective, open label, randomized, placebo controlled study checked the effects of ashwagandha root extract on physical performance. 30 healthy adult subjects were asked to take one capsules a day $330 \mathrm{mg}$ ashwagandha root extract $(\mathrm{n}=10)$, one capsules a day $500 \mathrm{mg}$ ashwagandha root extract $(\mathrm{n}=10)$, or placebo $(\mathrm{n}=10)$ for 4 weeks. Physical performance of the participants were assessed at the beginning, in the middle and at the end of the study by measuring: distance traveled and average speed in six minute cycle ergometer exercise test, muscle power using band grip strength by Jammers' hand held dynamometer, maximal aerobic capacity $\left(\mathrm{VO}_{2 \max }\right)$ in the YMCA Cycle Ergometer Submaximal Test. The measurement of blood pressure and heart rate was taken using cold pressor test and fixed workload exercise test on cycle ergometer. The results of this study showed statistically significant increase in distance traveled and average speed in both ashwagandha $330 \mathrm{mg} /$ day group and ashwagandha $500 \mathrm{mg}$ /day group $(\mathrm{p}<0.005)$ and statistically significant decrease in systolic blood pressure (in fixed workload exercise test on cycle ergometer) in both ashwagandha $330 \mathrm{mg} /$ day group and ashwagandha $500 \mathrm{mg}$ /day group $(\mathrm{p}<0.05)$ in comparison 
with the placebo group. There was no statistically significant difference in muscle power and $\mathrm{VO}_{2}$ max between ashwagandha $330 \mathrm{mg} /$ day group, ashwagandha $500 \mathrm{mg} /$ day group and placebo group. However there was increasing trend in muscle power and $\mathrm{VO}_{2 \max }$ in ashwagandha $330 \mathrm{mg} /$ day group and ashwagandha $500 \mathrm{mg}$ /day group; which was absent in placebo group. There was no statistically significant increasing dose effect present in any physical performance variable between ashwagandha $330 \mathrm{mg} /$ day group and ashwagandha $500 \mathrm{mg} /$ day group. No serious adverse effects were reported by the participants. So this study showed that ashwagandha root extract has a far greater beneficial effect on short term aerobic endurance [8].

\section{CONCLUSIONS}

1. Further trails, especially with a larger cohort and in more diverse populations, are needed to establish the role of ashwagandha root extract in improving physical performance.

2. There is also a need to determine the optimal dose of ashwagandha root extract and its application regimen in improving physical performance.

\section{REFERENCES:}

1. Malm C, Jakobsson J, Isaksson A. Physical Activity and Sports-Real Health Benefits: A Review with Insight into the Public Health of Sweden. Sports 2019;7(5):127

2. Triviño, JLP. Sport Enhancement: From Natural Doping to Brain Stimulation. Int. J. Technoeth. 2014,5:82-93.

3. Wankhede S, Langade D, Joshi K, Sinha SR, Bhattacharyya S. Examining the effect of Withania somnifera supplementation on muscle strength and recovery: a randomized controlled trial. J Int Soc Sports Nutr. 2015, 12:43.

4. Shenoy S, Chaskar U, Sandhu JS, Paadhi MM. Effects of eight-week supplementation of Ashwagandha on cardiorespiratory endurance in elite Indian cyclists. J Ayurveda Integr Med. 2012, 3(4):209-14.

5. Choudhary B, Shetty A, Langade DG. Efficacy of Ashwagandha (Withania somnifera [L.] Dunal) in improving cardiorespiratory endurance in healthy athletic adults. Ayu. 2015, $36(1): 63-8$. 
6. Sandhu JS, Shah B, Shenoy S, Chauhan S, Lavekar GS, Padhi MM. Effects of Withania somnifera (Ashwagandha) and Terminalia arjuna (Arjuna) on physical performance and cardiorespiratory endurance in healthy young adults. Int J Ayurveda Res. 2010, 1(3):144-9.

7. Malik A, Mehta V, Dahiya V. Effect of Ashwagandha (Withania somnifera) root powder supplementation on the VO2 max. and hemoglobin in hockey players. Int. J. Behav. Soc. Mov. Sci. 2013;2:91-99.

8. Tripathi RK, Salve BA, Petare AU, Raut AA, Rege NN. Effect of Withania somnifera on physical and cardiovascular performance induced by physical stress in healthy human volunteers. Int. J. Basic Clin. Pharmacol, 2016, 5: 2510-2516. 